\title{
DIE TUG OOR AMPSDRAERS TYDENS DIE DOLEANSIE VAN 1886
}

Dr. Jan Visser.

\section{Inleiding}

In art 29 van die Nederlandse Geloofsbelydenis word bely: "Die merktekens om die ware Kerk te ken is die volgende: As die Kerk die suiwere prediking van die evangelie uitoefen, as dit die suiwer bediening van die sakramente gebruik soos Christus dit ingestel het, as die kerklike tug gebruik word om die sondes te straf." Dit spreek vanself dat wanneer ampsdraers, aan wie Christus sy kudde toevertrou het (Hand 20:28), met leer en/of lewenswandel in sonde volhard en nie daarin met tug gestuit word nie, word die ware kerk nie gebou nie maar afgebreek. Ons sal later in hierdie artikel aantoon hoedanig die suiwer tug oor ampsdraers, veral leertug, tydens die Doleansie tot skade van die kerk van Christus agterweë gebly het.

A. Kuyper sê: verwaarlosing van die tug sny die gesag van Koning Jesus af. Daarom tas hierdie krankheid die wese van die kerk dodelik aan. Meestal ontstaan dit by die ouderlinge. Wanneer die geestelike en sedelike besef van plig en roeping kwyn, word hulle oplaas kragteloos en geesloos. Hulle laat geen tug meer oor hulleself oefen nie en het nie die moed om tug oor ander te oefen nie. (1883: 105-106). Paulus waarsku spesifiek teen die "wrede wolwe" wat onder die kudde sal inkom en hulle nie spaar nie. Hy het hier veral die dwaalleraars in gedagte, wat uit die gemeente self sal opstaan (Hand 20:29; vgl Grosheide $1948: 224-247$ ). Ge volglik sal ons verder aandui dat die kerkbesture nie begaan was oor die handhawing van die Belydenis, die suiwere leer en leertug nie, maar wel die (mens-gemaakte) reglemente wou handhaaf en streng toepas.

\section{Breë agtergrond}

\section{Die Algemene Reglement van 1816}

Wanneer die leërs van Napoleon Nederland in 1795 binnetrek, begin daar 'n proses wat in Augustus 1796 uitloop op besluit van die Nasionale Vergadering: "Er kan of zal geen bevoorregte noch heerschende kerk in Nederland meer geduld worden" (Van Loon, 1942: 22; Spoelstra, $1966: 30$; Berkhof, 1950:259). Napoleon word egter in 1815 verslaan en koning Willem I het na Nederland teruggekeer (Berkhof, 1950:260; Spoelstra 1966:30). H Bouwman (1928:312) beweer dat koning Willem I die Gereformeerde Kerke wou liberaliseer en daarvoor het hy die "Algemene Reglement..." laat ontwerp en op 7 Januarie 1816 afgekondig (Van Loon, 1942: 153; Lohman en Rutgers, $1887: 89$ ).

Hierdie Reglement is 'n toonbeeld van die kollegialistiese kerk. regeringstelsel. Sonder raadpleging van 'n kerklike vergadering en op 'n onwettige wyse het die staat dit op die kerke afgedwing. Die stelsel vertoon die kenmerke van die middeleeuse Caeseropapisme 
(die keiser is hoof van die kerk), die Lutherse staatskerk- of landskerk-stelsel, die Rewolusionêre staatsabsolutisme en die tipiese liberale onverskilligheid ten opsigte van die Belydenis. Daar is 'n hiërargie van k'erikalistiese (predikante) besture deur die koning aangestel en daarna deur hulleself aangevul. Die gemeente (wat in die Skrif die eintlike kerk vorm) is totaal onmondig gemaak. Hoewel 'n "klassis" behou is, was dit 'n blote kieskollege vir hoër besture, terwyl die predikante wat in Ringe verenig is, die eintlike regeerders vir die plaaslike kerk was (Spoe!stra, 1966:30, 31).

Die Reglement is ongereformeerd in inhoud. Die Gereformeerde Kerke is omskep in 'n genootskap wat van bo na onder bestuur is deur sinodale en mindere besture wat op hulle beurt in alles aan die regering ondergeskik was. So het 'n predikante bestuur oor die gemeente mag uitgeoefen, sonder enige verband met die kerkraad. Die gemeente moes slegs gehoorsaam. Die Gereformeerd-presibitereriale kerkinrigting is afgeskaf en vervang deur 'n kollegialistiese kerkinrigting (H Bouman, 1928: 312, 313; vgl Van der Walt, 1976 : 110-111).

\section{Die Algemene Reglement van 1852, as basis van die kerklike organisasie in $\mathbf{1 8 8 6}$}

In 1842 bepaal die regering dat die kerk voortaan sonder inmenging van die regering die kerkorde kan verander (K'eyn, 1888: 133). Op 20 Julie 1847 het die Sinode (buite die kerk om) begin met die revisie van die Algemene Reglement van 1816. Op 9 September 1851 is die reglement vasgestel en in 1852 deur koning Willem III goegekeur (Lohman en Rutgers, 1887:117-120). Die kerk het meer "selfstandig" teenoor die owerheid geword, nie deur toedoen van die kerk nie, maar deur die Koninklike Kerkbestuur. Die Reglement van 1852 berus nog heeltemal op die organisasie van 1816, wat verder bestendig en ontwikkel is (Lohman en Rutgers, 1887: 121 nota 1) en hoogstens gewysig is (Kleyn, 1888:133 vgl minister Nedermeijer van Rosenthal, rapport aan die koning, 13 Januarie 1851 by Rullmann, 1928:69).

Die Reglement van 1852 bepaal die hoogste wetgewende, regsprekende en besturende mag by die Sinode, al handel die Reglement eerstens oor die laere kerkbesture en laastens oor die hoëres. Die lede van die Sinode word gekies deur die Provinsiale Kerkbesture, wat op hulle beurt weer deur die klassisse gekies word. Alles gebeur sonder enige lasbrief. Die koning het die kerkbestuur nou vry gemaak van regeringsbande om met losser hande die kerk onderworpe te hou (Rullmann, 1928:67 ev).

H H Kuyper (1936:148-150) betoog dat die nuwe Reglement van 1852 die kerk nog steeds in slawerny gehou het en beslis geen terugkeer na die Skriftuurlik-presbiteriale kerkregering was nie. Die hiërargiese besture stelsel het onveranderd gebly. Van terugkeer na meerdere vergaderinge, waar die kerke self teenwoordig en verantwoordelik is met lasbriewe, was geen sprake nie. Kuyper sê dat kerkrade van hul godgegewe mag beroof is om tug te oefen oor predikante, ouderlinge en diakens. Skorsing en/of afsetting van ampsdraers het alleen by die hoër besture berus. Die toenemende 
mag van predikante het konsekwent gelei tot dominokrasie. Die ouderlinge het 'n baie beskeie regeerbevoegdheid oorgehou.

Die Nederlandse Hervormde Kerk het volgens die Reglement van 1852 uit al die Hervormde Gemeentes in die Koninkryk van die Nederlande bestaan (Kleyn 1888:137, 138). Kleyn praat gevolglik van 'n gemeente wat aan die Nederlandse Hervormde Kerk behoort.

Hier het ons dus die tipiese genootskaplike kollegialistiese kerkbegrip: Die kerkverband is die kerk en die plaaslike kerke is slegs afdelings daarvan. Begryplikerwys moet so 'n siening van kerkverband en plaaslike kerk ingrypende reperkussies hê vir die tug oor ampsdraers, veral vir die kerkraad en meerdere vergaderinge as subjekte van hierdie tug.

\section{"Jus constitutum" en "Jus constituendum"}

In die reformasie van 1886 het die begrippe "jus constitutum" en "jus constituendum" botsend teenoor mekaar te staan gekom.

Die Gereformeerde Kerkreg onderskei tussen die "jus constitutum" (die geldende reg) en die "jus constituendum" (die reg soos dit behoort te wees). Die geldende reg kan te kort skiet maar nie die reg wat Christus gegee het nie. Kerklike bepalings is dus geen absolute wet nie, maar reëlings wat uit die Woord van Christus, volgens die behoeftes van besondere omstandighede, in bepaalde tye afgelei is (H Bouman, $1928: 2$ ).

Die Hervormde Kerk in 1886 was (in kerkregtelike sin) soos 'n huis wat teen homself verdeeld was. Die "jus constitutum" en die "jus constituendum" het gebots. Gevolglik het daar spanning ontstaan tussen reg en plig. 'n Onhoudbare toestand het ontstaan: wie aan die Belydenis trou gebly het, het die reglemente geskend; en wie aan die reglemente trou gebly het, het die Belydenis geskend.

Om dus ' $n$ gebalanseerde en billike mening te vorm oor die tug oor ampsdraers tydens die Doleansie, sal deurgaans met botsing tussen jus constitutum en jus constituendum in die lig van die Skrifwoord "Ons moet God meer gehoorsaam wees as die mense" (Hand $5: 29$ ) gereken moet word.

\section{Hiërargie van Besture}

Uitgaande van die kardinale beginsel dat Christus Hoof is van sy kerk, reken die presbiteriale kerkreg met die plaaslike kerk as die selfstandige sigbare openbaring van die liggaam van Christus. Hierdie uitgangspunt vind sy grond in die Heilige Skrif, waar van die kerk gespreek word as 'n gemeenskap van bepaalde persone op 'n bepaalde plek (Van der Linde, $1965: 83$ ).

Kerke wat één is in Belydenis, Liturgie en Kerkregering mag nie los naasmekaar bestaan nie, maar vorm 'n kerkverband. In hierdie kerkverband gaan die selfstandigheid van die plaaslike kerke nie verlore nie. Daar kom nie deur die kerkverband 'n nuwe kerk tot stand nie. Die kerke in kerkverband word nie deur hoëre besture geregeer nie. Nee, kragtens die akkoord van kerklike gemeenskap waarop die kerkverband rus (die Belydenis), vind daar 'n gemeenskaplike handeling plaas deur middel van die onderskeie selfstandige kerke. Die samekomste van klassisse en sinodes is dus same- 
komste van meer kerke (en nie hoëre besture nie) ter wille van die kerkregering. Tydens die Doleansie van 1886 (soos trouens ook in die Afskeiding van 1834) was van hierdie presbiteriale beginsels mbt kerkverband en meerdere vergaderinge niks te sien nie. Hierdie toestand het luid geroep om reformasie, om terugkeer na die presbiteriale beginsel dat Christus as die Hoof van sy kerk, self gesag deur sy Woord en Gees uitoefen. Dit doen Hy nie deur middel van hiërargiese besture nie, maar deur ouderlinge wat wettig verkies, geroep en bevestig is.

\section{Enkele voorbeelde van hiërargiese dwang}

1 Die predikante $\mathrm{H}$ W A Verhoeff, A P A du Cloux (wat later tot "bekering" gekom het) en W Kraijenbelt dien by die Klassikale Bestuur van 's Gravenhage 'n formele aanklag in teen dr J C Zaal berg, met 'n beroep op art 11 van die "Algemene Reglement", waarby handhawing van die leer voorgeskryf word; Zaalberg het nie slegs die leer van die Hervormde Kerk nie, maar selfs dic grondwaarhede van die ganse Christendom aangerand en verwerp. Die aanklag van genoemde drie predikante beland egter in die doofpot; só veel so dat geen handboek oor kerkgeskiedenis daarvan melding maak nie. Die "Kerklijke Courant", offisiële orgaan van die Nederlandse Hervormde Kerk, adviseer in sy uitgawe van 13 Mei 1857 die Klassika!e Bestuur van 's Gravenhage om geen aandag aan die ingediende aanklag te gee nie, aangesien die klaers geen predikante van 's Gravenhage was nie en dus nie in betrekking tot die Klassikale Bestuur van 's Gravenhage gestaan het nie (Rullmann, $1928: 106-108$ ). Van leertug het hier dus niks tereggekom nie.

2 Reeds in 1875 besluit die Kerkraad van Amsterdam om die beheerreëlings só te wysig dat sy bevoegdheid insake beheer oor kerkeiendomme nooit op die Klassikale Bestuur sou oorgaan nie. Vir ruim 10 jaar het die beheer kalm verloop. Die vraag het toe ontstaan wat die posisie sou wees indien daar 'n breuk met die Sinodale Organisasie ontstaan waardeur tweërlei kerkrade na vore sou kom. Aan wie sou die kerkvoogdy dan verantwoordelik wees? Die Kerkraad besluit in 1885 dat die oorspronklike Kerkraad, wat die gemeente by Gods Woord wil hou, as die wettige erken moes word. Van die moderne predikante was teen hierdie besluit gekant en dien 'n klag in by die Klassikale Bestuur. Die Klassikale Bestuur het nie net die klag gelyk gegee nie, maar op 'n hiërargiese wyse 80 kerkraadslede geskors (Rullman, 1928:262, 263).

4 Die Kerkraadslede was ook die Kieskollege wat jaarliks ouderlinge en diakens verkies het. Op 11 Januarie 1886 kom die 303 lede van die kieskollege van Amsterdam byeen. Die Voorsitter (Westhoff) deel die Kieskollege mee dat ds Adriani, as Voorsitter van die Klassikale Bestuur, die 80 stemme van die geskorste kerkraadslede sal uitbring. Dit het teen alle reglemente en bepalinge gestry. Beswaar uit die vergadering word verwerp en 230 protesterendes verlaat die vergadering om apart te gaan beraadslaag. Hieroor word hulle egter weldra gesensureer (Rullmann, 1928:321, 322).

5 In die loop van 1886 bars 'n "vervolgingswoede" los in die 
hiërargiese Klassikale Bestuur van Rotterdam teen sekere ouderlinge van Rotterdam, wat daarop uitloop dat die Kerkraad op 5 Januarie 1887 die sinodale juk afwerp (Rullmann, $1929: 52-57$ ).

Die Doleansie van 1886 is dus uitsluitlik veroorsaak deurdat hiërargiese besture Christus as Hoof van sy kerk opsy geskuif het. Hulle het nie volgens Gods Woord nie, maar volgens menslike reglemente en eie willekeur die kerk oorheers.

\section{Die formulierekwessie}

Stryd het ook rondom die Formuliere van Eenheid so wel as die Ondertekeningsformuliere ontbrand.

Artikels 53 en 54 van die Kerkorde van die GKSA bepaal dat predikante, teologiese professore, ouderlinge, diakens en proponente die "drie Formuliere van Eenheid soos vasgestel op die Sinode van Dordrecht 1618-19", moet onderskryf en onderteken. Hulle moet openlik betuig dat die Belydenisskrifte met Gods Woord ooreenstem en as sodanig gehandhaaf sal word. Weiering of oortreding van die onderneming in die Ondertekeningsformulier, kan lei tot skorsing in en afsetting uit die diens en proponente tot intrekking van preekverlof (Gereformeerde Kerk in Suid-Afrika 1979: Kerkorde 25,26 en $82-84$ ).

Die presbiteriale kerkreg verbind dus Belydenis-formuliere en Ondertekenings formuliere onlosmaaklik aan mekaar so wel as aan amp en ampsbediening. Dit berus op die kardinale waarheid dat Christus Hoof is van sy kerk. Hy regeer deur sy Woord en Gees, waar Hy instrumentele gebruik van mense as sy dienaars maak. Die binding aan die Belydenis is ' $n$ binding aan die Woord van die Hoof. Die suiwerheid van die kerk is dus met die binding aan die suiwer Belydenis (dmv suiwer Ondertekeningsformuliere en gepaardgaande tug) lewensbelangrik gemoeid. Ook die kerkverband staan of val met Belydenis en Belydenis-binding omdat dit juis op die Belydenis as akkoord van kerklike gemeenskap rus.

Die hervormingsstryd in die Nederlandse Hervormde Kerk rondom 1886 was deurslaggewend 'n stryd om Belydenis en Belydenis-binding te handhaaf juis toe versuim van leertug sowel as ongeregverdigde toepassing van tug op ampsdraers wat die Belydenis wou handhaaf, sentraal na vore gekom het. Onderwerping aan menslike reglemente en besluite was vir die Besture belangriker as handhawing van en binding aan die Belydenis. Van die kant van die kerklike Besture was dit dus primêr 'n stryd om mag en selfhandhawing en nie 'n stryd om suiwerheid van die Kerk nie! Daar kon bitter-min tereg kom van die suiwere toepassing van die tug oor ampsdraers.

\section{Die Kerkbegrip}

Die gereformeerde kerkbegrip word geformuleer in artikels 27 en 28 van die Nederlandse Geloofsbelydenis, waar die kerk oa genoem word ' $n$ heilige vergadering van almal wat waarlik in Christus glo en waar dit as amp van alle gelowiges gestel word om af te skei van diegene wat nie tot die kerk behoort nie ( vgl V/A 54, Heid. Kate.). 
Art 29 (NGB) bely die merktekens waarmee die ware en valse kerk geken en van mekaar onderskei kan word. In die 19de eeu het die Nederlandse Hervormde Kerk as gevolg van afdwaling van die suiwere leer en nalatigheid van suiwere tug-toepassing, veral leertug, steeds duideliker die merktekens van die valse kerk vertoon. Dit het aan homself en sy ordinansies (reglemente) meer mag en gesag toegeskryf as aan die Woord van God (en die suiwere Belydenis wat daarop gegrond is). Hy wou hom aan die juk van Christus nie onderwerp nie, maar het deur middel van ongeregverdigde tug-aksies diegene vervolg wat "heilig lewe volgens die Woord van God" en die Kerk oor sy gebrekke en afdwalinge bestraf.

\section{DIE DOLEANSIE EN DIE LEERTUG}

\section{Die belangrikheid van leertug}

H. Bouwman sê tereg dat die leertug voortvloei uit die karakter van die kerk. Die kerk moet belydende kerk wees en die Belydenis handhaaf, soos die Skrif duidelik leer oa in I Tim 3:15, Gal $1: 8,9$ en 11 en II Joh 10 (1912:181-183). Dit word ook beklemtoon deur K Schilder (1960:257). Dr W A Hoek skryf egter in "Algemeen Weekblad" dat hy vir geen geld ter wêreld aan aktiewe leertug meedoen nie. Hy ag homself daarvoor te lelik en te ordinêr. Schilder antwoord hierop: "Ik mezelf ook", maar sy oordeel oor homself het geen waarde nie. God beveel en daarmee klaar. Daarom ag Schilder leertug noodsaaklik, en homself veels te lelik en te ordinêr om te besluit of hy wel met leertug sal begin of nie. As sy lelikwees en sy ordinêrwees hom van leertug moes afhou, moet dit hom tewens van léér afhou (kursivering oorspronklik). Ook Du Toit benadruk die noodsaaklikheid van leertug op sterkte van Ef $4: 14$, I Tim 4:6; II Tim 4:3; Tit $19: 9 ; 1: 11 ; 2: 1 ; 2: 8 ; 3: 10$; II Joh $: 9$.

Tereg sê Sadler $(1979: 63)$ dat 'n te lakse toepassing van die leertug tot indifferentisme en grenslose verdraagsaamheid lei. Hy meen dat leerdwaling by gewone kerklidmate met groter verdraagsaamheid bejeën kan word as by ampsdraers, veral leraars wie se afwyking soveel groter kwaad veroorsaak.

Die geskiedenis van die Christelike kerk gedurende die 19de eeu in Nederland, lewer onmiskenbare bewys van groot skade wat nalating van die leertug vir die kerk van Christus veroorsaak het.

\section{Die "aannemingskwessie"}

Rullmann (1928:204-205) verwys na die geval waar 'n katkisant hom vir belydenis by die moderne predikant, Ternooy Apél aangemeld het. Toe dit blyk dat hy die liggaamlike opstanding van Christus loën, weier die diensdoende ouderling om die akte van "aanneming" te voltrek. Ternooy Apél eis toe van die Kerkbesture om die Kerkraad te verplig om die katkisant as lidmaat van die kerk in te skryf. Die Kerkraad en die Klassikale Bestuur wys sy versoek af, maar die Provinsiale Kerkbestuur van Noord-Holland gee hom gelyk. Wanneer die Kerkraad hierdie uitspraak betwyfel, verklaar die Sinodale Kommissie die uitspraak van die Noord-Hollandse Provinsiale Kerkbestuur nietig en verwys die kwessie na die Pro- 
vinsiale Kerkbestuur van Groningen. Hierdie Bestuur gee in die middel van 1875 uitspraak op grond van 'n interpretasie van art 39 van die Reglement op Godsdiensonderwys, dat die hoëre Kerkbesture in 'n saak van "aanneming" niks te sê het nie en dat kerkrade in sulke sake kan doen wat hulle wil.

Soos begryplik is, het hierdie uitspraak totale willekeur in die hand gewerk. In een gemeente is vrysinnigheid gesanksioneer en in ' $n$ ander is die suiwere leer gehandhaaf. Vrysinnige katkisante uit ortodokse gemeentes en omgekeerd het in gemeentes volgens eie keuse belydenis van geloof gaan aflê en daarna met attestasie na die tuisgemeente teruggekeer. Die Sinode verander 15 Januarie 1879 art 38 van die Reglement op Godsdiensonderwys sò dat be sware teen die (onsuiwere) geloofsoortuigings van katkisante geen grond was om hulle af te wys van "aanneming" nie. Die Belydenis van die Kerk is prysgegee en die deur wyd oopgemaak vir alle vreemde leringe (Rullmann, 1928:209-210).

Soos later sal blyk, is ampsdraers wat hierteen in verset gekom het, deur die Kerkbesture getug. Dit was leertug dus in omgekeerde orde!

\section{Verandering van Proponentsformule}

Die Sinode van 1883 het art 27 van die "Reglement op het Examen ter toelating tot de Evangeliebediening" gewysig. Die Proponentsformule noem hierdeur selfs nie meer die Naam van Jesus Christus nie en proponente verbind hulleself slegs om "de belangen van het Godsrijk" te bevorder. Die laaste draad waarmee die Proponentsformule nog aan die leer van die Kerk verbonde was, is so deurgesny (Rullmann, 1928:239). Dit illustreer op nog 'n terrein hoe leertug oneervol gesneuwel het.

\section{Leertug en die volkskerk}

Rullmann (1928: 345 ) vermeld dat die Sinode in 1886 amptelik aan die Besture geskryf het dat die Hervormde Kerk die Volkskerk is en dat die gees van die tyd in hierdie Kerk gis. Daarom het die Kerklike Besture soveel moontlik aan elkeen se gewete oorgelaat om te bepaal of hy in die Hervormde Kerk sou kon bly. In die Volkskerk moet elkeen maar bepaal op watter voorwaardes hy lid of opsiener wil wees. Jy mag daar glo en preek wat jy wil. Rullmann sê tereg, die kerk sou ophou om kerk te wees. Alles gis in die tyd en werk ná in die kerk: Arminianisme, Pelagianisme, Remonstrantisme, Modernisme, Ateïsme.

In "De Doleantie en de Leertucht" sê Hepp (1936) dat die Hervormde Kerk in 1886 leertug oneervol ontslaan het en Doleansie in streng leertug die enigste middel gesien waardeur die dwalinge uitgesuiwer kon word en die Kerk sy Gereformeerde belydende karakter kon bewaar. Die Afskeiding (1834) moes die Gereformeerde Belydenis verdedig teen 'n Staatskerk, die Doleansie (1886) teen 'n Volkskerk (p. 123, 125; kursivering oorspronklik). Die Volkskerk het, sê Hepp, rampspoedige gevolge vir die leertug gehad ( $p$ 128). Slegs deur allerlei botsende rigtings in sy midde toe te laat en aan hulle gelyke regte en beskerming te verleen, kon hy die 
mensemassa byeen hou, wat hy as die volk aangedien het. Die Volkskerk en die leertug verdra mekaar nie ( $p$ 129).

Die Volkskerk lewer self die proef op die som. Die Doleansie dank sy akute ontstaan aan 'n beskeie poging om die leertug te herstel. Toe die Kerkraad van Amsterdam in Junie 1885 'n formule opgestel het wat onderteken moes word deur diegene wat attesta sie aangevra of voorgelê het, is predikante en ampsdraers, wat Skrif en Belydenis bokant die Reglemente gestel het, geskors en afgesit. Dit is die sonde van die Volkskerk: hy bring die wêreld in die kerk en verwoes daarmee die grense wat Christus en die apostels getrek het. Die Volkskerk veroorsaak spanning tussen waarheid en eenheid. Hy laat die waarheid tot 'n minimum daal en die eenheid tot 'n maksimum styg. Daardeur verkry hy egter nie die eenheid wat God welgevallig is nie. Die eenheid van die Volkskerk is administratief, reglementêr, veruitwendigd. Hy verkeer in 'n verwarring van geloofsverdeeldheid, waar selfs ongeloof in talle vertakkings sy intrede doen ( $p$ 129, 133, 136).

'n Kerk wat' die leertug in ere hou, sê Hepp tereg, dra sorg, sover dit binne sy vermoë is, dat slegs die waarheid van God vir hom gesag het. Waaragtige eenheid beteken om een te wees in die waarheid ( $p$ 136). Die beswaar dat leertug 'n kerk onverdraagsaam maak, verwring die aard van die leertug wat met onderskeiding handel. Die leertug is 'n gebod en ook 'n ryke gawe van Christus aan sy gemeente (Hepp 1936: p 142-143; kursiverings oor. spronklik).

Tereg beoordeel Rullmann en Hepp die kerklike organisasie van 1816 en 1852 as 'n donker ko! in die geskiedenis van die Christelike kerk, veral mbt leersuiwerheid, Belydenisbinding en leertug wat die kerk se wese as liggaam van Christus aantas.

\section{Bespreking van enkele tuggevalle}

Vroeër in hierdie artikel is reeds daarop gewys dat art 38 van die Reglement op Godsdiensonderwys deur die Sinode verander is sodat besware teen die (onsuiwere) geloofsoortuiging van Katkisante geen grond was om hulle weg te wys by "aanneming" nie. Hieruit het 'n paar tuggevalle voortgespruit waarop kortliks gewys kan word.

\section{Skorsing van die Dordtse ouderlinge}

As gevolg van gemelde verandering verklaar die ouderlinge van die gemeente Dordrecht dat hulle by geen "aanneming" van lidmate teenwoordig sou wees wanneer dit geskied deur predilkante wat die verandering van genoemde art 38 goedkeur nie. Nadat hulle deur die modernistiese leraars van Dordrecht aangekla is, vind sowel die Klassikale Bestuur van Dordrecht as die Provinsiale Kerk. bestuur van Suid-Holand hulle onskuldig (Rullmann, 1928:222). Die Sinode Kommissie vernietig egter die uitspraak en dra die saak vir eindbeslissing aan die Provinsiale Kerkbestuur van Gelderland op. Hierdie Bestuur skors al die Dordtse ouderlinge, ook dié wat slegs verklaar het dat hulle saamstem met die ander wat van die "aannemings" weggebly het (Rullmann, 1928:222-223). 


\section{Skorsing van di Eigeman en Van Hoogenhuyze}

Bogenoemde skorsing van al die Dordtse ouderlinge het 'n groot verwarring meegebring, want sonder ouderlinge kon daar geen kerkraadsvergaderings gehou word nie. Onder voorsitterskap van ds Eigeman word alle predikante, ouderlinge en diakens byeengeroep vir 'n kerkraadsvergadering. Geeneen van die modernistiese predikante woon die vergadering egter by nie. Die vergadering gee attestasies af en behandel die "aanneming" van lidmate. Ds Eigeman bevestig hulle. Vier lede van die Provinsiale Kerkbestuur dring daarna onwettig in die Kerkraad se sake in en doen oa diens by die "aanneming" van die leerlinge van die moderne predikante. Die geskorste Kerkraad weier om die name in die boeke te skryf. As gevolg van die verwarring weier ds Eigeman om nagmaal te bedien. Op 28 Julie 1880 word hy daarvoor deur die Provinsiale Kerkbestuur van Suid-Holland voorlopig geskors (Rullmann, 1928: 224-226).

Di Eigeman en Van Hoogenhuyze word later elk voor 'n "synodus contracta" gedaag. Ds Eigeman word vir 'n jaar en ds Van Hoogenhuyze vir vier weke geskors. Ds Eigeman het sogenaamd talle sondes teen die reglemente bedryf. Ds Van Hoogenhuyze het egter slegs geweier om die lidmateboek en die kerkraadsargief af te gee (Rullmann, 1928:227-228).

By die beoordeling van die skorsing van die ouderlinge on bogenoemde twee predikante van Dordrecht, val dit on dat hulle "oortreding" was dat hulle die suiwer leer in die kerk van Christus hoër geag en teenoor die reglemente gehandhaaf het. Die blatante kollegialistiese hiërargie van die kant van die verskillende Besture en Sinodale Kommissies toon duidelik hoe ver daar van die beginsels van die Skrif en die Gereformeerde kerkregering afge dwaal is.

\section{Skorsing en afsetting van ampsdraers in Amsterdam}

Die wysiging van art 38 van die Reglement op Godsdiensonderwys het ook in die Kerk van Amsterdam weerklank gevind. Die Kerkraad het besluit om Gods Woord in die "aanneming" van lidmate en die afgee van attestasies hoër te stel as die reglemente. Dit sou onvermydelik afstuur op 'n konflik met die sinodale organisasie (Rullmann, $1928: 241-254$ ).

Ander voorbeelde van hiërargie dwang is reeds gewys hoe die kerkraad die dreigende konflik voorsien het en homself tov beheer van sy eiendomme teenoor die sinodale organisasie wou beveilig (vgl Rullmann, 1928: 257-258).

Soos aangetoon het van die moderne predikante hulle teen dié reëling verset. Toe die kerkraad hulle beswaar van die hand wys, het twee van hulle die name van diegene, wat vir die maatreël gestem het, neergeskryf en aan die Klassikale Bestuur oorhandig. Op 4 Januarie 1886 skors die Klassikale Bestuur 5 predikante, 42 ouderlinge en 33 diakens voorlopig, sonder om hulle vooraf aan te hoor (Rullmann, 1928:259-265). Die Provinsiale Kerkbestuur sit op 1 Julie 188675 ampsdraers -5 van die geskorstes het tot "in- 
keer" gekom - uit hul kerklike bediening af. Appél by die "Synodus Contracta" en beswaar by die voltallige Sinode misluk. Op 1 Desember 1886 bekragtig die Sinode die afsetting (Rullmann, 1928: $343-344)$.

'n Tugoefening soos hierdie handhaaf nie reg nie, maar pleeg 'n skandelike onreg. Dit is bloot met die oog op hiërargiese handhawing van menslike reglemente en om die handhawing van eie posisie en die beveiliging van eie heerskappy gedoen. Van Gereformeerde kerkordelike beginsels en riglyne, gefundeer op die Woord van God, is hier geen sprake nie.

\section{Slot}

Het die Doleansie die gedagte van die plaaslike kerke só sterk op die voorgrond gestel dat daardeur (veral in later jare) die eenheid van die kerke in hul verband skade gely het? Dijk (1936:339) antwoord dat in 1886 eenheid bewaar is, maar dat later in Nederland uit die beginsel van die plaaslike kerk soms konklusies getrek is wat vir die kerkverband en die tugoefening deur die meerdere vergaderings skadelik was. Spoelstra sê: "Ongelukkig het die kerkregtelikes, soos F L Rutgers, $H$ Bouwman en andere, tog onbewus kerkraad en meerdere vergadering teenoor mekaar gestel en só die idee van die Hervormde Kerkbesture in 'n sekere sin op die meerdere vergaderinge gereflekteer. Hulle definieer laasgenoemdes tereg as vergaderinge van meer kerkrade, maar wanneer hulle oor die gesag van die meerdere vergaderinge handel, vergeet hulle dat dit kerkrade is wat daar vergader. Gevolglik wil hulle vir die meerdere vergaderinge gesag van die kerkrade aflei, asof die meerdere vergaderinge tog weer selfstandig buite die kerkrade (soos die Hervormde kerkbesture) bestaan en spreek daarom van afgeleide gesag. (Vgl Rutgers en De Savornin Lohman, aw, bl 22; H Bouman, Gereformeerd Kerkrecht, II, bl 18, 22). So raak hulle tog verseild in 'n valse probleem, omdat hulle onbewus met die kollegialistiese dualisme tussen plaaslike gemeente en algemene kerk rekening hou" (1966:34).

Om hierdie probleem te ontkom, moet daar in die kerk van Christus met net een gesag rekening gehou word: die gesag van Jesus Christus, die Koning van die kerk en hierdie gesag word bedien deur menslike instrumente. Daarom kan daar, streng ge sproke, nie gepraat word van die gesag van kerklike vergaderings nie. Daar is slegs die gesag van Christus wat in die vergaderings bedien word. (Visser, 1982:267 ev).

Meerdere vergaderings het wel tugreg, maar geen hiërargieskollegialistiese tugreg soos in die geval van die kerklike besture nie. Die tugreg moet die beginsels in art 30 en ander artikels van die Kerkorde streng handhaaf (kyk Visser, $1982: 304 \mathrm{ev}$ ).

Uit die Doleansie van 1886 blyk duidelik watter tragiese gevolge die genootskaplike hiërargies-kollegialistiese kerkbegrip, die degradering van die Belydenis, die afskaffing van Belydenis-binding en die nalating van die leertug vir die kerk van Jesus Christus gehad het. Hierdie dinge tas die kerk se eie wese as liggaam van Christus aan. 
Mag die Gereformeerde Kerke in Suid-Afrika by herdenking van die Doleansie 100 jaar gelede, opnuut heilige erns maak met die presbiteriaal-gereformeerde kerkregering, met die konsekwente handhawing van Belydenis en Belydenis-binding en met die nougesette toepassing van die tug, veral die leertug. Só sal ons Kerke dwalinge uitsuiwer en hul ware belydende karakter teen alle aanslae van die leuen bewaar.

\section{Bibliografie}

BERKHOF, H 1950. Geschiedenis der kerk. Nijkerk, Callenbach.

BOUWMAN, H 1912. De kerkelijke tucht. Kampen, Kok.

BOUWMAN. H 1928. Gereformeerd kerkrecht. Eerste deel. Kampen, Kok.

DIJK, K 1936. Het kerkbegrip der Doleantie. (In De reformatie van '86; gedenkboek bij het halve eeuwgetij der Doleantie. Kampen, Kok).

DU TOIT, J D 1961. Die sensuur. (In Versamelde werke van J D du Toit, VI : 445-454. Johannesburg, Dagbreek).

GEREFORMEERDE KERK IN SUID-AFRIKA. 1979. Kerkorde van die ...

GROSHEIDE, F W 1948. De handelingen der apostelen II. Hoofdstukken 15 28. (In Kommentaar op het Nieuwe Testament. Amsterdam, Van Bottenberg.

HEPP, V 1936. De Doleantie en de leertucht. (In De reformatie van '86; gedenkboek bij het halve eeuwgetij der Doleantie. Kampen, Kok).

KLEYN, H G 1888. Algemeene kerk en plaatslijke gemeente. Dordrecht, Morks.

KUYPER, A 1883. Tractaat van de reformatie der kerken. Amsterdam, Höveker.

KUYPER, H H 1936. De Doleantie en organisatie. (In De reformatie van '86; gedenkboek bij het halve eeuwgetij der Doleantie. Kampen, Kok).

LOHMAN, A F DE SAVORNIN EN RUTGERS, F I, 1887. De rechtsbevoegdheid onzer plaatselijke kerken. Amsterdam, Wormser.

RULLMANN, J C 1928. De strijd voor kerkherstel in de Nederlandsch Hervormde Kerk der XIXe eeuw. Kampen, Kok.

RULLMANN, J C 1929. De Doleantie in de Nederlandsch Hervormde Kerk der XIXe eeuw. Kampen, Kok.

SADLER, T H N 1979. Die kerklike tughandeling. Pretoria, NG Kerkboekhandel.

SCHILDER, K 1960. Leertucht. (In Verzamelde werken. De kerk I Goes, Oosterbaan en Le Cointre).

SPOELSTRA, B 1966. Inleiding. (In Kruger, L S, Du Plessis, H L M, Spoelstra, B, Spoelstra, T T. Handleiding by die kerkorde van die Gereformeerde Kerk in Suid-Afrika. p 11-41. Potchefstroom, Pro Rege).

VAN DER LINDE, G P L 1965. Die grondbeginsels van die presbiteriale kerkregering. Potchefstroom, Pro Rege.

VAN DER WALT, J 1976. Christus as Hoof van die kerk en die presbiteriale kerkregering. Potchefstroom, Pro Rege.

VAN LOON, J C A 1942. Het Algemeen Raglement van 1816. Wageningen, Gebr Zomer en Keuning.

VISSER, an 1982. Die tug oor ampsdraers. Ongepubliseerde ThD: Proefskrif PU vir CHO. 